\title{
The use of medications approved for Alzheimer's disease in autism spectrum disorder: a systematic review
}

\author{
Daniel A. Rossignol ${ }^{1 *}$ and Richard E. Frye ${ }^{2}$ \\ ${ }^{1}$ Rossignol Medical Center, Irvine, CA, USA \\ ${ }^{2}$ Arkansas Children's Hospital Research Institute, University of Arkansas for Medical Sciences, Little Rock, AR, USA
}

\section{Edited by:}

Roberto Canitano, University Hospital of Siena, Italy

Reviewed by:

Karen M. Smith, University of Louisiana at Lafayette, USA

Xiaoming Wang, Duke University, USA

*Correspondence:

Daniel A. Rossignol, Rossignol Medical Center, 16251 Laguna Canyon Road Suite 175, Irvine, CA 92618, USA

e-mail: rossignolmd@gmail.com
Autism spectrum disorder (ASD) is a neurodevelopmental disorder that affects 1 in 68 children in the United States. Even though it is a common disorder, only two medications (risperidone and aripiprazole) are approved by the U.S. Food and Drug Administration (FDA) to treat symptoms associated with ASD. However, these medications are approved to treat irritability, which is not a core symptom of ASD. A number of novel medications, which have not been approved by the FDA to treat ASD have been used off-label in some studies to treat ASD symptoms, including medications approved for Alzheimer's disease. Interestingly, some of these studies are high-quality, double-blind, placebo-controlled (DBPC) studies. This article systematically reviews studies published through April, 2014, which examined the use of Alzheimer's medications in ASD, including donepezil (seven studies, two were DBPC, five out of seven reported improvements), galantamine (four studies, two were DBPC, all reported improvements), rivastigmine (one study reporting improvements), tacrine (one study reporting improvements), and memantine (nine studies, one was DBPC, eight reported improvements). An evidence-based scale was used to rank each medication. Collectively, these studies reported improvements in expressive language and communication, receptive language, social interaction, irritability, hyperactivity, attention, eye contact, emotional lability, repetitive or self-stimulatory behaviors, motor planning, disruptive behaviors, obsessive-compulsive symptoms, lethargy, overall ASD behaviors, and increased REM sleep. Reported side effects are reviewed and include irritability, gastrointestinal problems, verbal or behavioral regression, headaches, irritability, rash, tremor, sedation, vomiting, and speech problems. Both galantamine and memantine had sufficient evidence ranking for improving both core and associated symptoms of ASD. Given the lack of medications approved to treat ASD, further studies on novel medications, including Alzheimer's disease medications, are needed.

\section{Keywords: autism, Alzheimer's disease, acetylcholinesterase inhibitors, NMDA antagonist, medications}

\section{BACKGROUND}

Autism spectrum disorder (ASD) is a heterogenous neurodevelopmental disorder that is defined by behavioral observations and characterized by developmental delays in communication and social interaction and by repetitive behaviors and/or restricted interests. The most recent prevalence of ASD in the United States (U.S.) is now 1 in 68 children, including 1 in 42 boys (1). Only two medications have been approved by the U.S. Food and Drug Administration (FDA) for ASD and these medications, risperidone and aripiprazole, are indicated to treat irritability, an associated but not core symptom of $\operatorname{ASD}(2,3)$. Since irritability is not a core feature of ASD, there are currently no U.S. FDA approved medications for treating the core symptoms of ASD.

A number of novel medications have been used to treat the symptoms of $\operatorname{ASD}(4,5)$. Some of these medications are approved for the treatment of Alzheimer's disease. A connection between Alzheimer's disease and autism has been proposed by some investigators (6) and will be reviewed below. Because of the evidence of this connection, several medications approved for Alzheimer's disease have been investigated for use in ASD.
To date, five medications have been approved by the U.S. FDA for the treatment of Alzheimer's disease: Tacrine (Cognex ${ }^{\circledR}$, 1993), Donepezil (Aricept $\left.{ }^{\circledR}, 1996\right)$, Rivastigmine (Exelon $\left.{ }^{\circledR}, 2000\right)$, Galantamine (Razadyne $\left.{ }^{\circledR}, 2001\right)$, and Memantine (Namenda ${ }^{\circledR}$, 2003). Donepezil, galantamine, rivastigmine, and tacrine are cholinesterase inhibitors, and work by preventing the breakdown of acetylcholine. Galantamine also stimulates nicotinic cholinergic receptors and therefore can increase the release of acetylcholine (7). Memantine is distinct from these other medications and modulates glutamate neurotransmission.

Several lines of evidence have implicated abnormalities in the cholinergic system in ASD (8). First, studies examining postmortem brain samples from individuals with ASD have reported abnormalities in the cholinergic system (9-11). Early studies compared the cholinergic system in frontal, parietal, hippocampus, and cerebellar tissue from typically developing adults to similarly aged autistic adults with intellectual disability. One of these studies found decreases in muscarinic $\mathrm{M}_{1}$ receptors in the parietal cortex and nicotinic receptors in the frontal and parietal cortexes, with a decrease in $\alpha_{4}$ and $\beta_{2}$ nicotinic subtypes confirmed 
by immunochemistry in the parietal cortex (9). Another study found significant changes in nicotinic receptors but no significant changes in muscarinic receptors or in the presynaptic cholinergic enzyme choline acetyltransferase in the cerebellum. Consistent nicotinic receptor changes included decreases in the $\alpha_{4}$ receptor subtype in several types of cells including granule and Purkinje cells, as well as increases in the $\alpha_{7}$ receptor subtype in the granule cell layer (11). In contrast, using quantitative receptor autoradiographic studies, no changes in cholinergic receptor binding were found in the hippocampus (12). Later, a study comparing typically developing and autistic adults showed a decrease in $\alpha_{7}$ and $\beta_{2}$ but not $\alpha_{4}$ nicotinic acetylcholine receptor subunits in the thalamus (10). Secondly, a positron emission tomography study reported a decrease in acetylcholinesterase activity in the bilateral fusiform gyri in ASD adults, as compared to typically developing adults, with this decrease correlated with objective scales of individual participant social disability (13). Thirdly, functional analysis of gene networks altered in individuals with ASD implicate synaptic cholinergic receptor families of genes (14) and epigenetic changes in both ASD and Rett syndrome have been linked to decreased expression of the CHRNA7 gene encoding the nicotinic receptor subtype $\alpha_{7}$ (15). Lastly, some studies have implicated cholinergic abnormalities in an animal model of ASD. The BTBR ASD mouse model demonstrates lower basal levels of extracellular acetylcholine in the prefrontal cortex (16) and injection of the acetylcholinesterase inhibitor donepezil into the BTBR mouse (systemically or directly) in the dorsomedial striatum, the rodent homolog of the caudate nucleus, ameliorated many core ASD behaviors (17). Thus, there is substantial support for the idea that treatments that modulate the cholinergic system might be helpful in ASD (18).

Several lines of scientific evidence have also pointed to abnormalities in glutamate metabolism in individuals with ASD as identified by imaging, genetic, and post-mortem studies. Proton magnetic resonance spectroscopy has demonstrated abnormalities in glutamate metabolism in individuals with ASD. For example, the glutamate + glutamine peak has been found to be increased in individuals with ASD as compared to controls in the auditory cortex (19), anterior cingulate cortex (20, 21), and basal ganglia (22). Another study found that the glutamate/glutamine ratio in the amygdala-hippocampal region was increased in ASD individuals as compared to controls (23), while one study found an increase in glutamate/creatine in the putamen in individuals with ASD (24). Interestingly, the magnetic resonance spectroscopy glutamate + glutamine peak in the basal ganglia of ASD individuals was correlated with a measure of impairment in social communication (22) and the glutamate/creatine ratio in the putamen was correlated with ASD symptoms (social interaction) (24). However, studies examining glutamate in frontal brain regions have demonstrated inconsistent results. For example, as compared to controls, individuals with ASD demonstrated a decrease in the GABA/glutamate ratio in the frontal cortex in one study (25) while the glutamate + glutamine peak was not different between ASD and control individuals in the prefrontal cortex in another study (22). The glutamate/creatine ratio was decreased in ASD individuals in the frontal lobes, as compared to controls, in another study (26).
Genetic studies have implicated abnormalities in ionotropic glutamate receptors in ASD. Genetic studies have associated ASD with abnormalities in subunits of $N$-methyl-D-aspartate (NMDA) (27-30), $\alpha$-amino-3-hydroxy-5-methyl-4-isoxazolepropionic acid (AMPA) $(31)$, and kainate $(32,33)$ receptors and the mitochondrial aspartate/glutamate carrier (34-36). Genetic syndromes that have a high prevalence of ASD features demonstrate abnormalities in glutamate neurotransmission. For example, haploinsufficiency of SHANK3, a gene that encodes postsynaptic scaffolding proteins for glutamate receptors, is characteristic of many patients with Phelan-McDermid syndrome, a genetic disorder with a high prevalence of ASD (37). Interestingly, genetic animal models of ASD have also demonstrated involvement of glutamate receptors. For example, one of the main areas of research is the Fragile $\mathrm{X}$ mouse model where abnormalities in metabotropic glutamate receptor subtype 5 (mGluR5) have been linked to behavioral and cognitive abnormalities that overlap symptoms associated with ASD (38).

Lastly, post-mortem studies have also implicated glutamate abnormalities. Cerebellum samples from individuals with ASD have demonstrated an increase in mRNA for AMPA 1, 2, and 3 receptors and glutamate/aspartate transporter 1 and 2 , an increase in protein levels of glutamate/aspartate transporter 1 and 2 and AMPA 1 and NMDA 1 receptors, but a decrease in AMPA receptor density (39). In addition, other studies have demonstrated an increase in mGluR5 protein in the vermis (40) and superior frontal cortex (41) of children with ASD. One study reported decreased levels of kidney-type glutaminase in the anterior cingulate cortex of individuals with ASD (42), while another study demonstrated an increase in the mitochondrial aspartate/glutamate carrier in the prefrontal cortex but not in the cerebellum of individuals with ASD (43). Thus, there is substantial evidence for glutamate abnormalities in individuals with ASD, suggesting the treatments that modulate glutamate may be helpful in ASD.

Memantine is an NMDA receptor antagonist and regulates the activity of glutamate, a neurotransmitter involved in memory and learning. Normally glutamate attaches to NMDA receptors allowing calcium to then enter freely into cells. Memantine prevents this by partially blocking NMDA receptors. Memantine has been reported to help obsessive-compulsive disorder (OCD) as well as impulsive behaviors in open-label (44-48), single blind (49), and placebo-controlled studies $(50,51)$. In animal models, memantine has also been shown to decrease evidence of neuroinflammation (52).

Given this background, this article reviews studies that have been published to date, which have reported on the use of these Alzheimer's medications in ASD individuals. Overall, this review demonstrates that there is significant scientific support for some of these medications in the treatment of core ASD symptoms, suggesting that further clinical trials may be helpful to help define the role for some of these medications for the treatment of individuals with ASD.

\section{METHODS}

\section{SEARCH STRATEGY}

A computer-aided search of PUBMED [website (http://www. ncbi.nlm.nih.gov/entrez)] and Google Scholar databases from 


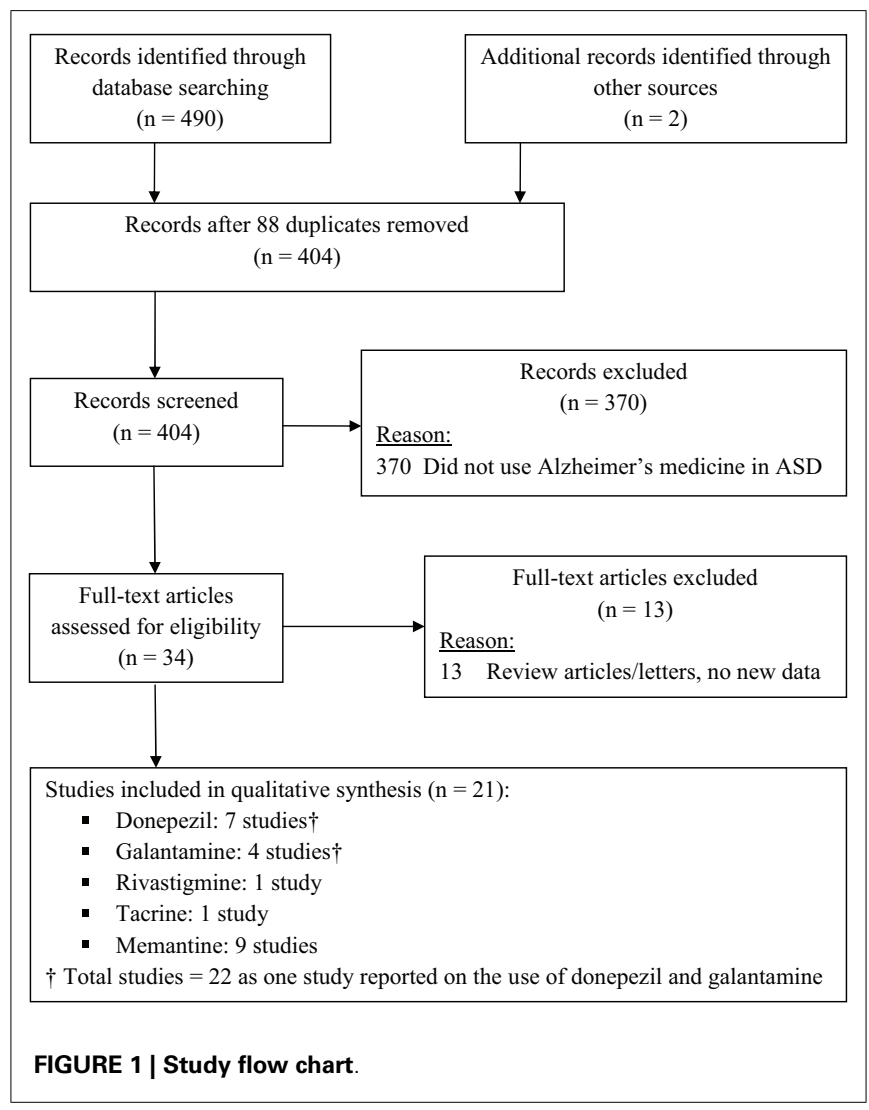

inception through the end of April, 2014 was conducted to identify pertinent articles using the search terms "autism," "autistic," "ASD," "pervasive developmental disorder," "PDD," and "Asperger" in all combinations with the terms: "donepezil," "galantamine," "memantine," "rivastigmine," "tacrine," "Alzheimer," "cholinesterase inhibitor," and "NMDA antagonist." The references cited in identified articles were also searched to locate additional studies (two studies total). Figure 1 depicts the studies identified during the search process.

\section{STUDY SELECTION}

Studies were included if they: (1) involved individuals with ASD, and (2) administered a medication approved for Alzheimer's disease to at least one individual with ASD. Articles that did not present new or unique data (such as review articles or letters to the editor) and animal studies were excluded. Studies on Rett syndrome and Childhood Disintegrative Disorder were also excluded. One reviewer screened titles and abstracts of all potentially relevant studies. After screening all records, 34 publications were identified and independently reviewed by both reviewers; 21 studies met inclusion criteria (see Figure 1). Within each section of this review, strengths and limitations of studies are discussed and recommendations for additional research are offered.

\section{LEVEL OF EVIDENCE RATINGS}

Although we considered conducting a meta-analysis on identified treatments, the lack of standard outcomes and the limitations in study design prevented a meta-analysis of any identified treatment.
Table 1 | Levels of evidence.

\begin{tabular}{|c|c|}
\hline Level & Description \\
\hline $1 a$ & $\begin{array}{l}\text { SR or meta-analysis of RCTs with homogeneity or Cochrane } \\
\text { review with favorable findings }\end{array}$ \\
\hline $1 b$ & Prospective high-quality RCT \\
\hline $2 a$ & $\begin{array}{l}\text { SR of cohort (prospective, non-randomized) studies with } \\
\text { homogeneity }\end{array}$ \\
\hline $2 b$ & $\begin{array}{l}\text { Individual cohort (prospective, non-randomized) study or } \\
\text { low-quality RCT }\end{array}$ \\
\hline 3a & SR of case-control (retrospective) studies with homogeneity \\
\hline $3 b$ & Individual case-control (retrospective) study \\
\hline 4 & Case-series or reports \\
\hline 5 & $\begin{array}{l}\text { Expert opinion without critical appraisal or based on physiology or } \\
\text { bench research }\end{array}$ \\
\hline
\end{tabular}

$R C T$, randomized controlled trial; SR, systematic review.

Table 2 | Grade of recommendation

\begin{tabular}{ll} 
Grade & Description \\
\hline A & At least one level 1a study or two level $1 \mathrm{~b}$ studies \\
B & At least one level $1 \mathrm{~b}, 2 \mathrm{a}$, or $3 a$ study, or two level $2 \mathrm{~b}$ or $3 \mathrm{~b}$ studies \\
C & At least one level $2 \mathrm{~b}$ or $3 \mathrm{~b}$ study, or two level 4 studies \\
D & Level 5 evidence, or troublingly inconsistent or inconclusive \\
& studies of any level, or studies reporting no improvements \\
N & No studies identified
\end{tabular}

As an alternative, we provide a grade of recommendation (GOR) for each treatment based on the level of evidence (LOE). Using a well-established scale (53), each study was individually assessed to determine the LOE, ranging from level 1 to 5 (Table 1). After assessing all identified studies for each treatment, a GOR ranging from A (solid evidence) to D (limited, inconsistent, or inconclusive evidence) was assigned (Table 2). Since a treatment could be a GOR of $\mathrm{D}$ for several reasons, we specified if the treatment received this rating because the evidence was a single case report or series (SC), was only based on bench research (BR), demonstrated an overall neutral effect (NE), or was found to be possibly detrimental (DE). If no studies were identified for a treatment, a GOR of $\mathrm{N}$ (no studies) was assigned. The overall ratings of Alzheimer disease medications used for ASD are found in Table 3. Table 4 lists the types of symptoms improved with each particular medication, while Table 5 compiles the side effects by medication.

\section{RESULTS}

DONEPEZIL

Seven studies reported on the use of donepezil in individuals with ASD, with five studies $(71 \%)$ reporting improvements. Five studies were open-label or retrospective case-series. The first identified study was an uncontrolled, retrospective, open-label study of eight children (LOE 4) with autistic disorder (mean age $11.0 \pm 4.1$ years) and reported improvements in irritability and hyperactivity with donepezil (up to $10 \mathrm{mg} /$ day) after at least 2 months of use; side effects included mild irritability (one patient) and gastrointestinal problems (nausea and vomiting in 1 patient) (54). Another 
uncontrolled, retrospective case-series (LOE 4) of eight children with PDD (ages 10-17 years) used donepezil (2.5-30 mg/day; mean 18 weeks of treatment) for ADHD-type symptoms and reported improvements in ADHD symptoms, communication,

Table 3 | Overall ratings of Alzheimer disease medications used for autism spectrum disorder.

\begin{tabular}{lccl}
\hline Medication & $\begin{array}{l}\text { Uncontrolled } \\
\text { studies positive } \\
\text { (positive/total) }\end{array}$ & $\begin{array}{l}\text { Controlled } \\
\text { studies positive } \\
\text { (positive/total) }\end{array}$ & $\begin{array}{l}\text { Grade of } \\
\text { recommendation }\end{array}$ \\
\hline Donepezil & $80 \%(4 / 5)$ & $50 \%(1 / 2)$ & $\mathrm{D}-\mathrm{NE}$ \\
Galantamine & $100 \%(2 / 2)$ & $100 \%(2 / 2)$ & $\mathrm{B}$ \\
Rivastigmine & $100 \%(1 / 1)$ & & $\mathrm{D}-\mathrm{SC}$ \\
Tacrine & $100 \%(1 / 1)$ & & $\mathrm{D}-\mathrm{SC}$ \\
Memantine & $88 \%(7 / 8)$ & $100 \%(1 / 1)$ & $\mathrm{B}$
\end{tabular}

and socialization; one patient had to stop the medication due to side effects (tremor, irritability, and distractibility) (55). An uncontrolled, open-label study (LOE 4) of five children with ASD (ages 2.5-6.9 years) with deficits in REM sleep administered donepezil, which increased the percentage of REM sleep as measured by polysomnography after 1 month of treatment (56). In a case report (LOE 4) of a 5-year-old child with ASD, treatment with donepezil ( $5 \mathrm{mg}$ at bedtime) over 6 weeks led to significant improvements in communication, eye contact, and hyperactivity (57). Finally, one case report (LOE 4 ) of three adults with autism treated with galantamine reported that the use of donepezil (dose not reported) led to verbal and behavioral regression in one adult (58).

Two studies were double-blind, placebo-controlled (DBPC) studies. The first DBPC study contained 43 children (LOE 1b) with autism (mean age 6.8 years) and administered donepezil or placebo over 6 weeks and reported improvements in expressive and receptive speech and a decrease in overall autistic behaviors in the treatment group; side effects included diarrhea and stomach

Table 4 | Improvements reported in studies of Alzheimer disease medications in ASD

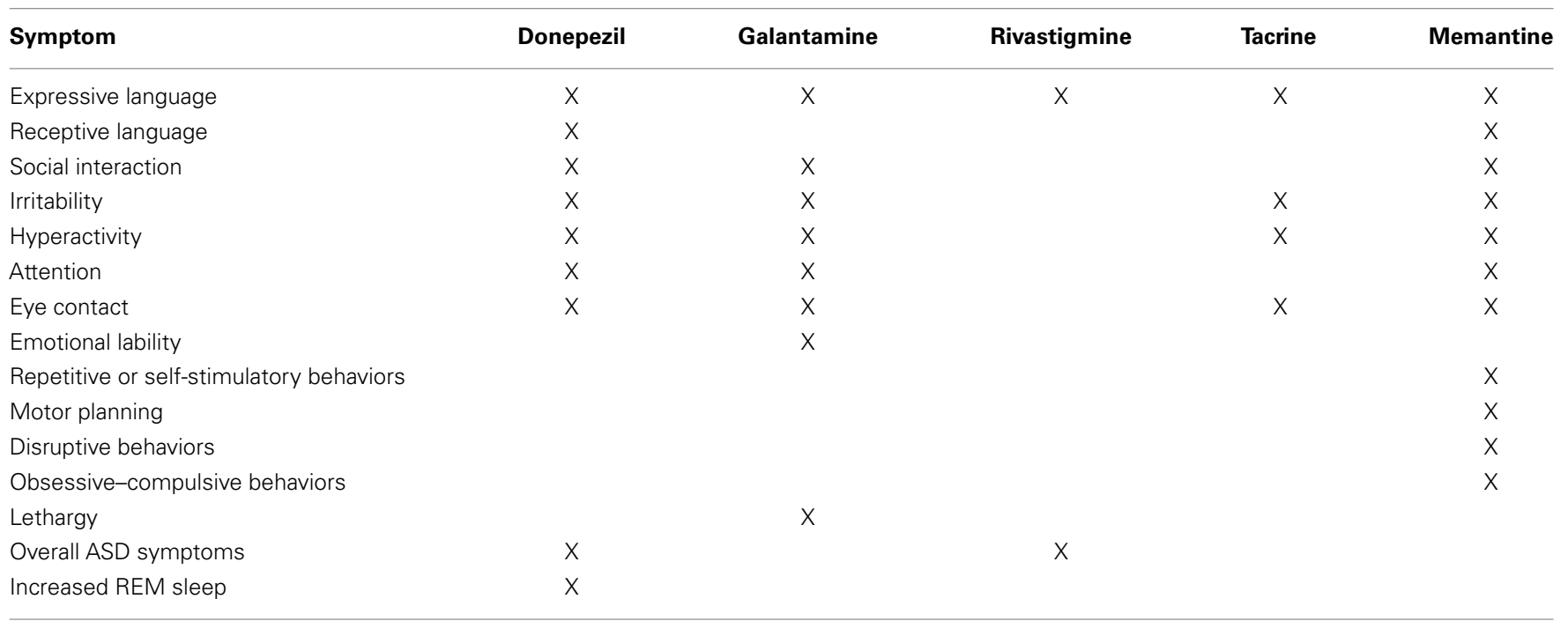

Table 5 | Reported side effects of Alzheimer disease medications in ASD.

\begin{tabular}{|c|c|c|c|c|c|}
\hline Side effect & Donepezil & Galantamine & Rivastigmine & Tacrine & Memantine \\
\hline Irritability & $x$ & & & & $x$ \\
\hline Gastrointestinal problems & $x$ & & & & $x$ \\
\hline Verbal or behavioral regression & $x$ & $x$ & & & \\
\hline Headaches & & $x$ & & & \\
\hline Worsened behaviors & & & & & $x$ \\
\hline Excessive sedation & & & & & $x$ \\
\hline Vomiting & & & & & $x$ \\
\hline Speech problems & & & & & $x$ \\
\hline Tremor & $x$ & & & & \\
\hline Distractibility & $x$ & & & & \\
\hline
\end{tabular}


cramps (59). In the second DBPC study of 34 children (LOE 1b) with ASD (age range 8-17 years), donepezil (dose 5-10 mg/day), or placebo was administered over 10 weeks, with a 10 -week openlabel trial of the medication for children in the placebo group who did not respond. No significant improvements were found in the donepezil group compared to the placebo group; no serious adverse events were observed (60).

Overall, the evidence for donepezil is inconsistent for improvements in ASD symptoms as one of the two DBPC studies was negative and one of the five case-series reported detrimental effects rather than beneficial effects of donepezil. As two case-series reported improvements in ADHD symptoms and one case-series demonstrated improvements in REM sleep, donepezil may have favorable effects on subsets of children with ASD who have these specific symptoms. Clearly, several studies have demonstrated favorable effects of donepezil, suggesting that further studies focused on specific symptoms may be warranted in the future.

\section{GALANTAMINE}

Four studies reported on the use of galantamine in individuals with ASD, with all four studies reporting improvements. Two of the studies were uncontrolled, open-label, or case-series (LOE 4). In the first case-series (LOE 4 ) of three adults with autism (21 to 42 years old), galantamine $4-16 \mathrm{mg}$ /day was reported to increase expressive language and communication; however; one individual had a regression when put on donepezil (58). The second study was a 12-week, uncontrolled, open-label study (LOE 4) of galantamine in 13 children with autism (mean age $8.8 \pm 3.5$ years), which reported improvements in parent-rated social withdrawal and irritability on the Aberrant Behavior Checklist (ABC) and improvements in attention and emotional lability on the Conner's Parent Rating Scale - Revised; eight patients were rated as improved on the Clinical Global Impression Scale (CGI); no significant adverse effect were found except for headaches in one child (61).

Two studies were DBPC. The first DBPC study of 20 children (LOE 2b) with autism (mean age $7.4 \pm 3.2$ years) reported a significant improvement with galantamine (dose not noted) compared to placebo on the ABC in irritability, eye contact, hyperactivity, and inappropriate speech; side effects were minimal (62). The second DBPC study of 40 children (LOE 1 b) with autism (ages 4-12 years) reported that galantamine (up to $24 \mathrm{mg} /$ day) for 10 weeks led to significant improvements in lethargy/social withdrawal and irritability on the ABC compared to placebo; side effects were similar in both groups (18).

Given that galantamine has been shown to improve both core and associated ASD symptoms in both open-label and DBPC studies (one high-quality and one of lower quality), it is given a GOR of B. Given this preliminary positive evidence, it is clear that large multicenter high-quality controlled trials should be conducted to provide efficacy data to further define the role of galantamine in the treatment of ASD.

\section{RIVASTIGMINE}

An open-label study of 32 children (LOE 4) with autism used rivastigmine (0.4-0.8 $\mathrm{mg}$ twice a day) for 12 weeks and reported improvements in expressive speech and overall autism symptoms
(63). Given the limited number of studies on rivastigmine for the treatment of ASD, this treatment is given a GOR of D - SC. Because of the positive preliminary results and the fact that it was well tolerated, further larger open-label or blinded studies may be warranted for this treatment in ASD.

\section{TACRINE}

An open-label study of three individuals (LOE 4) with ASD (mean age $17.4 \pm 33.2$ years) administered $20 \mathrm{mg}$ of tacrine daily and reported mild improvements in irritability, hyperactivity, eye contact, and inappropriate speech as rated by combined parent and teacher scales (ABC); no significant side effects were reported (64). Given the limited number of studies on tacrine for the treatment of ASD, this treatment is given a GOR of D - SC. Because of the positive preliminary results and the fact that it was well tolerated, further studies may be warranted for this treatment in ASD to see if a wider number of children with ASD respond to this treatment.

\section{MEMANTINE}

Nine studies reported on the use of memantine in individuals with ASD, with eight studies (89\%) reporting improvements. Eight studies were open-label or retrospective case-series. In the first study, Chez et al. (63) administered open-label (LOE 4) memantine (mean dose $8.1 \mathrm{mg} /$ day, range $2.5-10 \mathrm{mg} /$ day) in 30 children (mean age 8.92 years) with ASD and reported that for those treated more than 8 weeks (mean duration 18 weeks, range $8-40$ weeks), 16 (53\%) demonstrated significant improvements and $10(33 \%)$ showed more mild improvements in attention, eye contact, language (expressive and receptive), repetitive behaviors, and motor planning; no significant side effects were observed (65). One case report (LOE 4) described the effects of memantine on a 23-yearold man with autistic disorder and observed improvements in disruptive behavior with memantine $10 \mathrm{mg} /$ day over an 8-month period (66). An uncontrolled, open-label (LOE 4) study of 151 individuals with ASD (ages 2.58-26.33 years old) used memantine at a dose ranging from 2.5 to $30 \mathrm{mg}$ and reported improvements in language, self-stimulatory behaviors, and social behavior; 22 patients (15\%) had worsened behavior as a side effect (67).

An uncontrolled, open-label, and retrospective study (LOE 4) examined the effects of memantine (maximum dose $20 \mathrm{mg}$ /day; duration of use 1.5-56 weeks) in 18 children with ASD (age 619 years) and reported improvements in social withdrawal and inattention; 7 patients (39\%) had side effects including irritability (4 patients), rash (1 patient), excessive sedation and vomiting (1 patient), and an increase in seizures ( 1 patient); 4 patients had to discontinue memantine (68). An uncontrolled, open-label (LOE 4) study of four patients with ASD (mean age 17.4 \pm 33.2 years) administered memantine $20 \mathrm{mg}$ daily for 4 weeks and reported significant improvements on combined parent and teacher ratings on the ABC in irritability, hyperactivity, and inappropriate speech $(p<0.05$ for all three); no side effects were reported (69). An uncontrolled, open-label study (LOE 4) used memantine (starting at $5 \mathrm{mg}$, increasing every 2 weeks up to $20 \mathrm{mg} /$ day; mean final dose $18.3 \pm 2.6 \mathrm{mg} /$ day; mean use $34.7 \pm 36.5$ weeks, range 8-104 weeks) in six individuals with Fragile $\mathrm{X}$ and concomitant PDD (mean age $18.3 \pm 3.8$ years, range $13-22$ years; four had autistic disorder and two had PDD). Four of the six patients were rated 
as "much improved" or "very much improved" on the CGI; nonsignificant improvements were observed on the ABC and SRS; two individuals experienced irritability, which led to drug discontinuation (70). A case report ( $\mathrm{LOE} 4$ ) of a 15-year-old boy with Asperger disorder, OCD, and Tourette disorder described the use of memantine ( $2.5 \mathrm{mg}$ increasing to $10 \mathrm{mg} / \mathrm{day})$ to treat the OCD symptoms and observed a significant reduction in OCD symptoms, including rituals and intrusive thoughts as well as improvements in social interaction; no significant adverse events were observed (71). One case study (LOE 4) reported stuttering and speech loss in two children with ASD who were taking memantine; in one child the speech improved with stopping the medication, while in the other child it improved while continuing the medication (72).

Only one study was DBPC and was a 10-week study of 40 children (LOE 1b) with ASD (ages 4-2 years). This study administered memantine (up to $15 \mathrm{mg} /$ day if $10-40 \mathrm{~kg} ; 20 \mathrm{mg}$ /day if over $40 \mathrm{~kg})$ compared to placebo and reported significant improvements on the $\mathrm{ABC}$ in irritability $(p<0.001)$, stereotypy $(p<0.01)$, and hyperactivity/non-compliance $(p<0.01)$; side effects were similar in both groups (73).

Given that the majority of clinical studies, including a DPBC study, provide positive evidence of improvements in both core and associated ASD symptoms, a GOR of B is provided for memantine for the treatment of ASD. Several studies have outlined adverse effects in certain patients with memantine treatment. Interestingly, memantine has been reported to both improve and worsen irritability. This suggests that there might be specific subgroups of children with ASD that respond optimally to memantine. Clearly larger, well-designed, and blinded studies are needed to further evaluate the efficacy of memantine in children with ASD as well as define the subgroups that might optimally respond to this medication.

\section{DISCUSSION}

This manuscript reviews the evidence for the use of medications which are FDA approved for Alzheimer's disease in individuals with ASD. These medications target two neurotransmitter systems, acetylcholine and glutamate, which are both neurotransmitter systems with abnormalities associated with ASD. Overall five medications, four which target acetylcholine neurotransmission and one that targets glutamate neurotransmission, which are FDA indicated for Alzheimer's disease have been used in individuals with ASD. To provide recommendations on the evidence for the potential usefulness of these medications for the treatment of ASD, we used an objective scale to rate the evidence for the utility of these medications for treating core and associated symptoms of ASD. Overall, we found that one medication that targets acetylcholine neurotransmission, galantamine, and one medication that targets glutamate neurotransmission, memantine, have reasonable evidence for the treatment of core and associated symptoms of ASD, although both require larger controlled studies to provide further efficacy data and define subgroups of individuals with ASD who may best respond to these treatments with limited adverse effects. Two medications, rivastigmine and tacrine, both of which target the acetylcholine neurotransmitter system, have only preliminary uncontrolled studies to support their use, so further studies need to be performed before recommendations can be made. One medication that targets acetylcholine, donepezil, has several studies investigating its use in individuals with ASD but the results of some of the studies, particularly the DBPC studies, are inconsistent, making recommendations difficult at this time, although in certain subgroups (ADHD symptoms or REM sleep problems) it might be of use.

Given the fact that there is no FDA approved medication for the core symptoms of ASD and considering the limited proven effective treatments for ASD, studies are needed to identify novel treatments. Because several of the medications reviewed here show promising evidence for effectiveness for treating core and associated ASD symptoms, such medications should undergo further study in clinical trials to confirm their effectiveness for treating individuals with ASD.

\section{ACKNOWLEDGMENTS}

The review did not receive any financial or grant support from any sources.

\section{REFERENCES}

1. Developmental Disabilities Monitoring Network Surveillance Year 2010 Principal Investigators; Centers for Disease Control and Prevention (CDC). Prevalence of autism spectrum disorder among children aged 8 years - autism and developmental disabilities monitoring network, 11 sites, United States, 2010. MMWR Surveill Summ (2014) 63(Suppl 2):1-21.

2. Scott LJ, Dhillon S. Risperidone: a review of its use in the treatment of irritability associated with autistic disorder in children and adolescents. Paediatr Drugs (2007) 9(5):343-54. doi:10.2165/00148581-200709050-00006

3. Ghanizadeh A, Sahraeizadeh A, Berk M. A head-to-head comparison of aripiprazole and risperidone for safety and treating autistic disorders, a randomized double blind clinical trial. Child Psychiatry Hum Dev (2014) 45(2):185-92. doi:10.1007/s10578-013-0390-x

4. Frye RE, Rossignol D, Casanova MF, Brown GL, Martin V, Edelson S, et al. A review of traditional and novel treatments for seizures in autism spectrum disorder: findings from a systematic review and expert panel. Front Public Health (2013) 1:31. doi:10.3389/fpubh.2013.00031

5. Rossignol DA. Novel and emerging treatments for autism spectrum disorders: a systematic review. Ann Clin Psychiatry (2009) 21(4):213-36.

6. Sokol DK, Maloney B, Long JM, Ray B, Lahiri DK. Autism, Alzheimer disease, and fragile X: APP, FMRP, and mGluR5 are molecular links. Neurology (2011) 76(15):1344-52. doi:10.1212/WNL.0b013e3182166dc7

7. Woodruff-Pak DS, Vogel RW III, Wenk GL. Galantamine: effect on nicotinic receptor binding, acetylcholinesterase inhibition, and learning. Proc Natl Acad Sci U S A (2001) 98(4):2089-94. doi:10.1073/pnas.98.4.2089

8. Deutsch SI, Urbano MR, Neumann SA, Burket JA, Katz E. Cholinergic abnormalities in autism: is there a rationale for selective nicotinic agonist interventions? Clin Neuropharmacol (2010) 33(3):114-20. doi:10.1097/WNF. 0b013e3181d6f7ad

9. Perry EK, Lee ML, Martin-Ruiz CM, Court JA, Volsen SG, Merrit J, et al. Cholinergic activity in autism: abnormalities in the cerebral cortex and basal forebrain Am J Psychiatry (2001) 158(7):1058-66. doi:10.1176/appi.ajp.158.7.1058

10. Ray MA, Graham AJ, Lee M, Perry RH, Court JA, Perry EK. Neuronal nicotinic acetylcholine receptor subunits in autism: an immunohistochemical investigation in the thalamus. Neurobiol Dis (2005) 19(3):366-77. doi:10.1016/j.nbd. 2005.01.017

11. Lee M, Martin-Ruiz C, Graham A, Court J, Jaros E, Perry R, et al. Nicotinic receptor abnormalities in the cerebellar cortex in autism. Brain (2002) 125(Pt 7):1483-95. doi:10.1093/brain/awf160

12. Blatt GJ, Fitzgerald CM, Guptill JT, Booker AB, Kemper TL, Bauman ML. Density and distribution of hippocampal neurotransmitter receptors in autism: an autoradiographic study. J Autism Dev Disord (2001) 31(6):537-43. doi:10.1023/ A:1013238809666

13. Suzuki K, Sugihara G, Ouchi Y, Nakamura K, Tsujii M, Futatsubashi M, et al. Reduced acetylcholinesterase activity in the fusiform gyrus in adults with autism spectrum disorders. Arch Gen Psychiatry (2011) 68(3):306-13. doi:10.1001/archgenpsychiatry.2011.4 
14. Lee TL, Raygada MJ, Rennert OM. Integrative gene network analysis provides novel regulatory relationships, genetic contributions and susceptible targets in autism spectrum disorders. Gene (2012) 496(2):88-96. doi:10.1016/j.gene.2012. 01.020

15. Yasui DH, Scoles HA, Horike S, Meguro-Horike M, Dunaway KW, Schroeder DI, et al. 15q11.2-13.3 chromatin analysis reveals epigenetic regulation of CHRNA7 with deficiencies in Rett and autism brain. Hum Mol Genet (2011) 20(22):4311-23. doi:10.1093/hmg/ddr357

16. McTighe SM, Neal SJ, Lin Q, Hughes ZA, Smith DG. The BTBR mouse model of autism spectrum disorders has learning and attentional impairments and alterations in acetylcholine and kynurenic acid in prefrontal cortex. PLoS One (2013) 8(4):e62189. doi:10.1371/journal.pone.0062189

17. Karvat G, Kimchi T. Acetylcholine elevation relieves cognitive rigidity and social deficiency in a mouse model of autism. Neuropsychopharmacology (2014) 39(4):831-40. doi:10.1038/npp.2013.274

18. Ghaleiha A, Ghyasvand M, Mohammadi MR, Farokhnia M, Yadegari N, Tabrizi $\mathrm{M}$, et al. Galantamine efficacy and tolerability as an augmentative therapy in autistic children: a randomized, double-blind, placebo-controlled trial. J Psychopharmacol (2014) 28(7):677-85. doi:10.1177/0269881113508830

19. Brown MS, Singel D, Hepburn S, Rojas DC. Increased glutamate concentration in the auditory cortex of persons with autism and first-degree relatives: a (1)H-MRS study. Autism Res (2013) 6(1):1-10. doi:10.1002/aur.1260

20. Bejjani A, O’Neill J, Kim JA, Frew AJ, Yee VW, Ly R, et al. Elevated glutamatergic compounds in pregenual anterior cingulate in pediatric autism spectrum disorder demonstrated by 1 H MRS and 1H MRSI. PLoS One (2012) 7(7):e38786. doi:10.1371/journal.pone.0038786

21. Bernardi S, Anagnostou E, Shen J, Kolevzon A, Buxbaum JD, Hollander E, et al. In vivo $1 \mathrm{H}$-magnetic resonance spectroscopy study of the attentional networks in autism. Brain Res (2011) 1380:198-205. doi:10.1016/j.brainres. 2010.12.057

22. Horder J, Lavender T, Mendez MA, O'Gorman R, Daly E, Craig MC, et al. Reduced subcortical glutamate/glutamine in adults with autism spectrum disorders: a [(1)H]MRS study. Transl Psychiatry (2013) 3:e279. doi:10.1038/tp. 2013.53

23. Page LA, Daly E, Schmitz N, Simmons A, Toal F, Deeley Q, et al. In vivo $1 \mathrm{H}$ magnetic resonance spectroscopy study of amygdala-hippocampal and parietal regions in autism. Am J Psychiatry (2006) 163(12):2189-92. doi:10.1176/appi. ajp.163.12.2189

24. Doyle-Thomas KA, Card D, Soorya LV, Wang AT, Fan J, Anagnostou E. Metabolic mapping of deep brain structures and associations with symptomatology in autism spectrum disorders. Res Autism Spectr Disord (2014) 8(1):44-51. doi:10.1016/j.rasd.2013.10.003

25. Harada M, Taki MM, Nose A, Kubo H, Mori K, Nishitani H, et al. Non-invasive evaluation of the GABAergic/glutamatergic system in autistic patients observed by MEGA-editing proton MR spectroscopy using a clinical 3 tesla instrument. J Autism Dev Disord (2011) 41(4):447-54. doi:10.1007/s10803-010-1065-0

26. Kubas B, Kulak W, Sobaniec W, Tarasow E, Lebkowska U, Walecki J. Metabolite alterations in autistic children: a 1H MR spectroscopy study. Adv Med Sci (2012) 57(1):152-6. doi:10.2478/v10039-012-0014-x

27. O’Roak BJ, Vives L, Girirajan S, Karakoc E, Krumm N, Coe BP, et al. Sporadic autism exomes reveal a highly interconnected protein network of de novo mutations. Nature (2012) 485(7397):246-50. doi:10.1038/nature10989

28. Yoo HJ, Cho IH, Park M, Yang SY, Kim SA. Family based association of GRIN2A and GRIN2B with Korean autism spectrum disorders. Neurosci Lett (2012) 512(2):89-93. doi:10.1016/j.neulet.2012.01.061

29. Barnby G, Abbott A, Sykes N, Morris A, Weeks DE, Mott R, et al. Candidategene screening and association analysis at the autism-susceptibility locus on chromosome 16p: evidence of association at GRIN2A and ABAT. Am J Hum Genet (2005) 76(6):950-66. doi:10.1086/430454

30. Tarabeux J, Kebir O, Gauthier J, Hamdan FF, Xiong L, Piton A, et al. Rare mutations in $N$-methyl-D-aspartate glutamate receptors in autism spectrum disorders and schizophrenia. Transl Psychiatry (2011) 1:e55. doi:10.1038/tp. 2011.52

31. Ramanathan S, Woodroffe A, Flodman PL, Mays LZ, Hanouni M, Modahl CB, et al. A case of autism with an interstitial deletion on $4 \mathrm{q}$ leading to hemizygosity for genes encoding for glutamine and glycine neurotransmitter receptor subunits (AMPA 2, GLRA3, GLRB) and neuropeptide receptors NPY1R, NPY5R. BMC Med Genet (2004) 5:10. doi:10.1186/1471-2156-5-10
32. Jamain S, Betancur C, Quach H, Philippe A, Fellous M, Giros B, et al. Linkage and association of the glutamate receptor 6 gene with autism. Mol Psychiatry (2002) 7(3):302-10. doi:10.1038/sj.mp.4000979

33. Shuang M, Liu J, Jia MX, Yang JZ, Wu SP, Gong XH, et al. Family-based association study between autism and glutamate receptor 6 gene in Chinese Han trios. Am J Med Genet B Neuropsychiatr Genet (2004) 131B(1):48-50. doi:10.1002/ajmg.b.30025

34. Hong CJ, Liou YJ, Liao DL, Hou SJ, Yen FC, Tsai SJ. Association study of polymorphisms in the mitochondrial aspartate/glutamate carrier SLC25A12 (aralar) gene with schizophrenia. Prog Neuropsychopharmacol Biol Psychiatry (2007) 31(7):1510-3. doi:10.1016/j.pnpbp.2007.07.010

35. Ramoz N, Reichert JG, Smith CJ, Silverman JM, Bespalova IN, Davis KL, et al. Linkage and association of the mitochondrial aspartate/glutamate carrier SLC25A12 gene with autism. Am J Psychiatry (2004) 161(4):662-9. doi:10.1176/ appi.ajp.161.4.662

36. Segurado R, Conroy J, Meally E, Fitzgerald M, Gill M, Gallagher L. Confirmation of association between autism and the mitochondrial aspartate/glutamate carrier SLC25A12 gene on chromosome 2q31. Am J Psychiatry (2005) 162(11):2182-4. doi:10.1176/appi.ajp.162.11.2182

37. Phelan K, McDermid HE. The 22q13.3 Deletion Syndrome (Phelan-McDermid Syndrome). Mol Syndromol (2012) 2(3-5):186-201.

38. D’Antoni S, Spatuzza M, Bonaccorso CM, Musumeci SA, Ciranna L, Nicoletti F, et al. Dysregulation of group-I metabotropic glutamate (mGlu) receptor mediated signalling in disorders associated with Intellectual Disability and Autism. Neurosci Biobehav Rev (2014). doi:10.1016/j.neubiorev.2014.02.003

39. Purcell AE, Jeon OH, Zimmerman AW, Blue ME, Pevsner J. Postmortem brain abnormalities of the glutamate neurotransmitter system in autism. Neurology (2001) 57(9):1618-28. doi:10.1212/WNL.57.9.1618

40. Fatemi SH, Folsom TD, Kneeland RE, Liesch SB. Metabotropic glutamate receptor 5 upregulation in children with autism is associated with underexpression of both Fragile X mental retardation protein and GABAA receptor beta 3 in adults with autism. Anat Rec (Hoboken) (2011) 294(10):1635-45. doi:10.1002/ar.21299

41. Fatemi SH, Folsom TD. Dysregulation of fragile $\mathrm{x}$ mental retardation protein and metabotropic glutamate receptor 5 in superior frontal cortex of individuals with autism: a postmortem brain study. Mol Autism (2011) 2:6. doi:10.1186/2040-2392-2-6

42. Shimmura C, Suzuki K, Iwata Y, Tsuchiya KJ, Ohno K, Matsuzaki H, et al. Enzymes in the glutamate-glutamine cycle in the anterior cingulate cortex in postmortem brain of subjects with autism. Mol Autism (2013) 4(1):6. doi:10.1186/2040-2392-4-6

43. Lepagnol-Bestel AM, Maussion G, Boda B, Cardona A, Iwayama Y, Delezoide $\mathrm{AL}$, et al. SLC25A12 expression is associated with neurite outgrowth and is upregulated in the prefrontal cortex of autistic subjects. Mol Psychiatry (2008) 13(4):385-97. doi:10.1038/sj.mp.4002120

44. Aboujaoude E, Barry JJ, Gamel N. Memantine augmentation in treatmentresistant obsessive-compulsive disorder: an open-label trial. J Clin Psychopharmacol (2009) 29(1):51-5. doi:10.1097/JCP.0b013e318192e9a4

45. Grant JE, Odlaug BL, Mooney M, O’Brien R, Kim SW. Open-label pilot study of memantine in the treatment of compulsive buying. Ann Clin Psychiatry (2012) 24(2):119-26.

46. Pasquini M, Biondi M. Memantine augmentation for refractory obsessivecompulsive disorder. Prog Neuropsychopharmacol Biol Psychiatry (2006) 30(6):1173-5. doi:10.1016/j.pnpbp.2006.04.013

47. Feusner JD, Kerwin L, Saxena S, Bystritsky A. Differential efficacy of memantine for obsessive-compulsive disorder vs. generalized anxiety disorder: an open-label trial. Psychopharmacol Bull (2009) 42(1):81-93.

48. Grant JE, Chamberlain SR, Odlaug BL, Potenza MN, Kim SW. Memantine shows promise in reducing gambling severity and cognitive inflexibility in pathological gambling: a pilot study. Psychopharmacology (Berl) (2010) 212(4):603-12. doi:10.1007/s00213-010-1994-5

49. Stewart SE, Jenike EA, Hezel DM, Stack DE, Dodman NH, Shuster L, et al. A single-blinded case-control study of memantine in severe obsessivecompulsive disorder. J Clin Psychopharmacol (2010) 30(1):34-9. doi:10.1097/ JCP.0b013e3181c856de

50. Ghaleiha A, Entezari N, Modabbernia A, Najand B, Askari N, Tabrizi M, et al. Memantine add-on in moderate to severe obsessive-compulsive disorder: randomized double-blind placebo-controlled study. J Psychiatr Res (2013) 47(2):175-80. doi:10.1016/j.jpsychires.2012.09.015 
51. Haghighi M, Jahangard L, Mohammad-Beigi $H$, Bajoghli $H$, Hafezian $H$, Rahimi A, et al. In a double-blind, randomized and placebo-controlled trial, adjuvant memantine improved symptoms in inpatients suffering from refractory obsessive-compulsive disorders (OCD). Psychopharmacology (Berl) (2013) 228(4):633-40. doi:10.1007/s00213-013-3067-z

52. Rosi S, Vazdarjanova A, Ramirez-Amaya V, Worley PF, Barnes CA, Wenk GL. Memantine protects against LPS-induced neuroinflammation, restores behaviorally-induced gene expression and spatial learning in the rat. Neuroscience (2006) 142(4):1303-15. doi:10.1016/j.neuroscience.2006.08.017

53. Howick J, Chalmers I, Glasziou P, Greenhalgh T, Heneghan C, Liberati A, et al. The Oxford 2011 Levels of Evidence: Oxford Centre for Evidence-Based Medicine. (2011). Available from: http://www.cebm.net/index.aspx?o=5653

54. Hardan AY, Handen BL. A retrospective open trial of adjunctive donepezil in children and adolescents with autistic disorder. J Child Adolesc Psychopharmacol (2002) 12(3):237-41. doi:10.1089/104454602760386923

55. Doyle RL, Frazier J, Spencer TJ, Geller D, Biederman J, Wilens T. Donepezil in the treatment of ADHD-like symptoms in youths with pervasive developmental disorder: a case series. J Atten Disord (2006) 9(3):543-9. doi:10.1177/ 1087054705284091

56. Buckley AW, Sassower K, Rodriguez AJ, Jennison K, Wingert K, Buckley J, et al. An open label trial of donepezil for enhancement of rapid eye movement sleep in young children with autism spectrum disorders. J Child Adolesc Psychopharmacol (2011) 21(4):353-7. doi:10.1089/cap.2010.0121

57. Srivastava RK, Agarwal M, Pundhir A. Role of donepezil in autism: its conduciveness in psychopharmacotherapy. Case Rep Psychiatry (2011) 2011:563204. doi:10.1155/2011/563204

58. Hertzman M. Galantamine in the treatment of adult autism: a report of three clinical cases. Int J Psychiatry Med (2003) 33(4):395-8. doi:10.2190/JE5Q1NFT-FL40-7PMW

59. Chez MG, Buchanan TM, Becker M, Kessler J, Aimonovitch MC, Mrazek SR. Donepezil hydrochloride: a double-blind study in autistic children. J Pediatr Neurol (2003) 1(2):83-8.

60. Handen BL, Johnson CR, McAuliffe-Bellin S, Murray PJ, Hardan AY. Safety and efficacy of donepezil in children and adolescents with autism: neuropsychological measures. J Child Adolesc Psychopharmacol (2011) 21(1):43-50. doi:10.1089/cap.2010.0024

61. Nicolson R, Craven-Thuss B, Smith J. A prospective, open-label trial of galantamine in autistic disorder. J Child Adolesc Psychopharmacol (2006) 16(5):621-9. doi:10.1089/cap.2006.16.621

62. Niederhofer H, Staffen W, Mair A. Galantamine may be effective in treating autistic disorder. BMJ (2002) 325(7377):1422. doi:10.1136/bmj.325.7377.1422/a

63. Chez MG, Aimonovitch M, Buchanan T, Mrazek S, Tremb RJ. Treating autistic spectrum disorders in children: utility of the cholinesterase inhibitor rivastigmine tartrate. J Child Neurol (2004) 19(3):165-9.

64. Niederhofer H. Treating autism pharmacologically: also tacrine might improve symptomatology in some cases. J Child Neurol (2007) 22(8):1054. doi:10.1177/ 0883073807305857
65. Chez M, Hung PC, Chin K, Memon S, Kirschner S. Memantine experience in children and adolescents with autistic spectrum disorders. Ann Neurol (2004) 56(8 Suppl):109. doi:10.1002/ana.20263

66. Erickson CA, Chambers JE. Memantine for disruptive behavior in autistic disorder. J Clin Psychiatry (2006) 67(6):1000. doi:10.4088/JCP.v67n0619h

67. Chez MG, Burton Q, Dowling T, Chang M, Khanna P, Kramer C. Memantine as adjunctive therapy in children diagnosed with autistic spectrum disorders: an observation of initial clinical response and maintenance tolerability. J Child Neurol (2007) 22(5):574-9. doi:10.1177/0883073807302611

68. Erickson CA, Posey DJ, Stigler KA, Mullett J, Katschke AR, McDougle CJ. A retrospective study of memantine in children and adolescents with pervasive developmental disorders. Psychopharmacology (Berl) (2007) 191(1):141-7. doi:10.1007/s00213-006-0518-9

69. Niederhofer H. Glutamate antagonists seem to be slightly effective in psychopharmacologic treatment of autism. J Clin Psychopharmacol (2007) 27(3):317-8. doi:10.1097/01.jcp.0000270082.30500.69

70. Erickson CA, Mullett JE, McDougle CJ. Open-label memantine in fragile X syndrome. J Autism Dev Disord (2009) 39(12):1629-35. doi:10.1007/s10803-0090807-3

71. Bernhardt EB, Walsh KH, Posey DJ, McDougle CJ. Memantine for comorbid obsessive-compulsive disorder and Asperger disorder suggests a link in glutamatergic dysregulation. J Clin Psychopharmacol (2011) 31(5):673-5. doi:10. 1097/JCP.0b013e31822c92d4

72. Alaghband-Rad J, Nikvarz N, Tehrani-Doost M, Ghaeli P. Memantine-induced speech problems in two patients with autistic disorder. Daru (2013) 21(1):54. doi:10.1186/2008-2231-21-54

73. Ghaleiha A, Asadabadi M, Mohammadi MR, Shahei M, Tabrizi M, Hajiaghaee R, et al. Memantine as adjunctive treatment to risperidone in children with autistic disorder: a randomized, double-blind, placebo-controlled trial. Int J Neuropsychopharmacol (2013) 16(4):783-9. doi:10.1017/S1461145712000880

Conflict of Interest Statement: The authors declare that the research was conducted in the absence of any commercial or financial relationships that could be construed as a potential conflict of interest.

Received: 11 May 2014; accepted: 01 August 2014; published online: 22 August 2014. Citation: Rossignol DA and Frye RE (2014) The use of medications approved for Alzheimer's disease in autism spectrum disorder: a systematic review. Front. Pediatr. 2:87. doi: $10.3389 /$ fped.2014.00087

This article was submitted to Child and Neurodevelopmental Psychiatry, a section of the journal Frontiers in Pediatrics.

Copyright $(\odot) 2014$ Rossignol and Frye. This is an open-access article distributed under the terms of the Creative Commons Attribution License (CC BY). The use, distribution or reproduction in other forums is permitted, provided the original author (s) or licensor are credited and that the original publication in this journal is cited, in accordance with accepted academic practice. No use, distribution or reproduction is permitted which does not comply with these terms. 